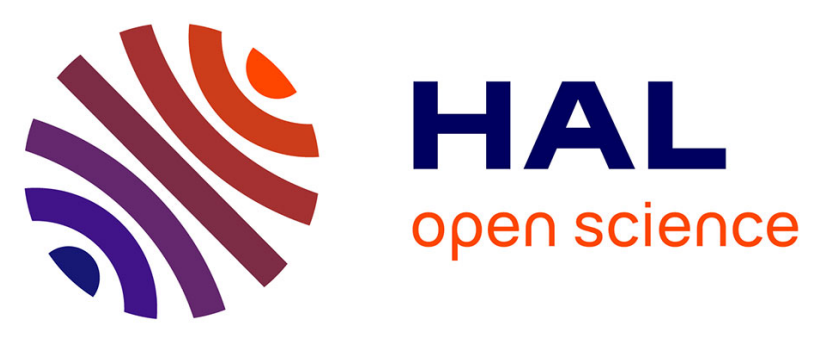

\title{
Poleward transport variability in the Northern Hemisphere during final stratospheric warmings simulated by CESM(WACCM)
}

Rémi Thiéblemont, Katja Matthes, Yvan J Orsolini, Alain Hauchecorne, Nathalie Huret

\section{To cite this version:}

Rémi Thiéblemont, Katja Matthes, Yvan J Orsolini, Alain Hauchecorne, Nathalie Huret. Poleward transport variability in the Northern Hemisphere during final stratospheric warmings simulated by CESM(WACCM). Journal of Geophysical Research: Atmospheres, 2016, 121 (18), pp.10394-10410. 10.1002/2016JD025358 . insu-01371298

\section{HAL Id: insu-01371298 \\ https://hal-insu.archives-ouvertes.fr/insu-01371298}

Submitted on 29 Nov 2016

HAL is a multi-disciplinary open access archive for the deposit and dissemination of scientific research documents, whether they are published or not. The documents may come from teaching and research institutions in France or abroad, or from public or private research centers.
L'archive ouverte pluridisciplinaire HAL, est destinée au dépôt et à la diffusion de documents scientifiques de niveau recherche, publiés ou non, émanant des établissements d'enseignement et de recherche français ou étrangers, des laboratoires publics ou privés. 


\section{Journal of Geophysical Research: Atmospheres}

\section{RESEARCH ARTICLE \\ 10.1002/2016JD025358 \\ Key Points: \\ - The CESM(WACCM) model realistically \\ Poleward transport variability in the Northern Hemisphere during final stratospheric warmings simulated by CESM(WACCM)} simulates frozen-in anticyclones (FrlACs) during stratospheric final warmings

- FrlAC occurrences are favored after winters without major sudden stratospheric warmings

- FrIACs preferentially develop under an easterly phase of the quasi-biennial oscillation in the middle stratosphere

Correspondence to:

R. Thiéblemont,

remi.thieblemont@latmos.ipsl.fr

\section{Citation:}

Thiéblemont, R., K. Matthes, Y. J. Orsolini, A. Hauchecorne, and N. Huret (2016), Poleward transport variability in the Northern Hemisphere during final stratospheric warmings simulated by CESM(WACCM), J. Geophys. Res. Atmos., $121,10,394-10,410$, doi:10.1002/ 2016JD025358.

Received 13 MAY 2016 Accepted 25 AUG 2016

Accepted article online 28 AUG 2016 Published online 17 SEP 2016

O2016. American Geophysical Union All Rights Reserved.

\author{
Rémi Thiéblemont ${ }^{1,2}$, Katja Matthes ${ }^{1,3}$, Yvan J. Orsolini ${ }^{4}$, Alain Hauchecorne ${ }^{5}$, and Nathalie Huret ${ }^{6,7}$ \\ ${ }^{1}$ GEOMAR-Helmholtz Centre for Ocean Research, Kiel, Germany, ${ }^{2}$ Now at Laboratoire Atmosphères, Milieux, Observations \\ Spatiales-IPSL, CNRS, Paris, France, ${ }^{3}$ Faculty of Mathematics and Natural Science, Christian-Albrechts-Universität zu Kiel, \\ Kiel, Germany, ${ }^{4}$ Norwegian Institute for Air Research, Kjeller, Norway, ${ }^{5}$ Laboratoire Atmosphères, Milieux, Observations \\ Spatiales-IPSL, CNRS, Guyancourt, France, ${ }^{6}$ Laboratoire de Physique et Chimie de l'Environnement et de l'Espace, CNRS, \\ Orléans, France, ${ }^{7}$ U. F. R. Sciences, Université d'Orléans, Orléans, France
}

Abstract Observational studies of Arctic stratospheric final warmings have shown that tropical/subtropical air masses can be advected to high latitudes and remain confined within a long-lived "frozen-in" anticyclone (FrIAC) for several months. It was suggested that the frequency of FrIACs may have increased since 2000 and that their interannual variability may be modulated by (i) the occurrence of major stratospheric warmings (mSSWs) in the preceding winter and (ii) the phase of the quasi-biennial oscillation (QBO). In this study, we tested these observational-based hypotheses for the first time using a chemistry climate model. Three 145 year sensitivity experiments were performed with the National Center of Atmospheric Research's Community Earth System Model (CESM): one control experiment including only natural variability, one with an extreme greenhouse gas emission scenario, and one without the QBO in the tropical stratosphere. In comparison with reanalysis, the model simulates a realistic frequency and characteristics of FrIACs, which occur under an abrupt and early winter-to-summer stratospheric circulation transition, driven by enhanced planetary wave activity. Furthermore, the model results support the suggestion that the development of FrlACs is favored by an easterly QBO in the middle stratosphere and by the absence of mSSWs during the preceding winter. The lower stratospheric persistence of background dynamical state anomalies induced by deep mSSWs leads to less favorable conditions for planetary waves to enter the high-latitude stratosphere in April, which in turn decreases the probability of FrIAC development. Our model results do not suggest that climate change conditions (RCP8.5 scenario) influence FrIAC occurrences.

\section{Introduction}

Stratospheric final warming (hereafter SFW) marks the springtime dynamical transition during which the polar vortex irreversibly breaks up and the associated strong winter cyclonic circulation (westerly) reverses to the weaker summer anticyclonic circulation (easterly). Due to combined radiative and planetary wave forcing effects, the timing and dynamical characteristics of SFWs are highly variable from one year to another, which in turn has important repercussions on stratospheric ozone depletion [e.g., Manney et al., 2011] and troposphere circulation and predictability [Black et al., 2006; Ayarzagüena and Serrano, 2009; Hardiman et al., 2011]. Hence, a better understanding of the atmospheric dynamical conditions driving SFW interannual variability is of noticeable interest.

One approach to characterize SFW dynamical variability is to analyze the persistent spatial structures in dynamical fields (e.g., potential vorticity (PV)) or long-lived trace gases (tracers) in spring and summer. Hess [1990, 1991] studied the polar vortex breakup using both a general circulation model and Limb Infrared Monitor of the Stratosphere (LIMS) observations and found that debris (or remnants) of the polar vortex can persist as coherent vortices for several months after the final warming, being "frozen in" in the summertime easterly flow. Orsolini [2001] found evidence of polar vortex remnants persisting in the Northern Hemisphere extratropical stratosphere until August in 3-D transport simulations of long-lived tracers. Observation of vortex remnants in summer Northern Hemisphere midlatitudes was later on confirmed by in situ balloon measurements [Durry and Hauchecorne, 2005]. By examining the interannual variability of the characteristics of the Arctic vortex breakup from 1958 to 2002, Waugh and Rong [2002] showed that vortex remnants persist a couple of months longer during early breakup years (February and March) compared to late breakup years (April and May). 
More recent studies have shown that low-latitude air could similarly be transported to the polar region around the time of the SFW and persist for several months within an anticyclonic anomaly embedded in summer easterlies. Manney et al. [2006] reported, for the first time, a "frozen-in" anticyclone (FrIAC) in the polar stratosphere during 2005 spring and summer using $\mathrm{H}_{2} \mathrm{O}$ and $\mathrm{N}_{2} \mathrm{O}$ observations from the Microwave Limb Sounder (MLS). This FrIAC event started as a low-latitude intrusion which was quickly advected poleward during the SFW and developed into an anticyclone extending in the vertical range 650-1400 K (or $~ 25-40 \mathrm{~km}$ ). Following Manney's pioneering study, several new FrlACs have been identified using either satellite observations of long-lived tracers or dynamical passive tracer transport simulations, in the springs of 2003 [Lahoz et al., 2007], 2007 [Thiéblemont et al., 2011], 2011 [Allen et al., 2012; Adams et al., 2013], and 2013 [Siskind et al., 2015].

Observed FrIACs generally occur under strong and abrupt SFWs which are associated to a strong enhancement of planetary wave activity [e.g., Thiéblemont et al., 2011]. The detailed modeling studies of the 2005 [Allen et al., 2011] and 2011 [Allen et al., 2013] FrlACs provided a thorough description of the FrlAC life cycle. This can be divided into three phases: (1) a "spin-up" phase in which the FrlAC develops and is advected to the polar region, (2) an "anticyclonic" phase in which the FrIAC is trapped in the developing summer easterlies and resists the weak vertical wind shear (April-May), and finally (3) a "shearing" phase in which the anticyclonic anomaly decays due to diabatic processes and the tracer anomaly is sheared out by the background wind (beginning by the end of May).

In addition, two climatologies of FrIACs starting in 1979 [Allen et al., 2012] and 1960 [Thiéblemont et al., 2013] and based on MERRA (Modern Era-Retrospective Analysis for Research and Applications) and ECMWF ERA-40/ ERA-Interim (European Centre for Medium-Range Weather Forecasts Re-Analysis) reanalyses, respectively, were performed. Despite the use of different reanalyses, transport models, and FrIAC detection algorithms, both studies revealed largely consistent results with common FrlACs identified in the springs of 1982, 1994, 1997, 2002, 2003, 2005, and 2011. Discrepancies were found for cases identified in the springs of 2000, 2004 [Allen et al., 2012], and 2007 [Thiéblemont et al., 2011] and are mostly due to the difference in the criteria used to define what a FrIAC is. In brief, Allen et al. [2012] established their FrIAC climatology based on the intensity of easterlies after the SFW and the identification of anomalous low-latitude air masses over the pole (northward of $80^{\circ} \mathrm{N}$ ). Thiéblemont et al. [2013] identified FrIACs by requiring low-latitude air masses in the polar region (northward of $60^{\circ} \mathrm{N}$ ) to be colocated with an anticyclonic eddy until, at least, the beginning of the shearing phase (see Thiéblemont et al. [2013] for a detailed discussion).

Although no trend in FrIAC occurrence could be determined (given the limited record), both climatologies noticed a strong increase in FrlAC frequency after 2000. Thiéblemont et al. [2011, 2013] also suggested that FrIACs preferentially occur in years without major sudden stratospheric warmings ( $\mathrm{mSSWs}$ ) in the previous winter and under the easterly phase of the quasi-biennial oscillation (QBO) in the tropical middle stratosphere $(\sim 10 \mathrm{hPa}$ or $30 \mathrm{~km})$. These findings are, however, challenged by the limited number of FrlACs that have been recorded in reanalyses and satellite observations. Moreover, a FrlAC was detected in 2013 [Siskind et al., 2015], while neither of the two previously mentioned criteria applied; i.e., a mSSW occurred in January 2013 [Bailey et al., 2014; Manney et al., 2015], and the zonal wind circulation in the tropical region was westerly at $10 \mathrm{hPa}$.

Here we use for the first time a fully coupled chemistry climate model to examine the dynamical variability of the winter-to-summer transition associated with FrIACs. The principal motivation of this study was to determine whether such models are able to simulate FrIACs and whether the stratosphere dynamical preconditions favoring SFWs with FrIAC occurrences suggested by previous work are robust. The paper is organized as follows. Section 2 describes the model, the reanalysis, and the model experimental setup used in our study. In section 3, the FrlAC identification algorithm is described and applied to both model and reanalysis in order to assess the model performance. Section 4 examines the stratosphere dynamics associated with FrIACs in the different model experiments. Section 5 focuses on the influence of $\mathrm{mSSWs}$ and the tropical zonal wind flow on FrIACs. Finally, section 6 is devoted to summary and discussion.

\section{Model and Data}

\subsection{Model and Reanalysis}

We used the Community Earth System Model (CESM), developed at the National Center for Atmospheric Research (NCAR). CESM is a state-of-the-art fully coupled model which includes an interactive ocean (POP), 
Table 1. Summary of CESM(WACCM) Experiments

\begin{tabular}{lccc} 
Name & Period & GHGs and ODSs & QBO \\
\hline Natural & $1955-2099(145$ years $)$ & Fixed at 1960 s level & Nudged \\
RCP85 & $1955-2099(145$ years $)$ & Observations and RCP8.5 scenario & Nudged \\
NoQBO & $1955-2099(145$ years $)$ & Fixed at 1960 s level & No \\
\hline
\end{tabular}

land (CLM), sea ice (CICE), and an atmospheric component with interactive chemistry (WACCM3.5) [Marsh et al., 2013]. WACCM3.5 [Gent et al., 2011] has a horizontal resolution of $2.5^{\circ} \times 1.9^{\circ}$ (longitude $\times$ latitude) and 66 vertical levels which extend from the Earth's surface up to $140 \mathrm{~km}$. Chemistry is calculated interactively in the chemistry module based on version 3 of the Model for OZone And Related chemical Tracers (MOZART) [Kinnison et al., 2007]. WACCM3.5 includes spectrally daily resolved solar variability from the NRLSSI1 data set [Lean et al., 2005]. Since the vertical resolution is not high enough to internally generate a QBO, the modeled tropical zonal winds are relaxed to observations between $22^{\circ} \mathrm{S}$ and ${ }^{\circ} \mathrm{N}$, using a Gaussian weighting function with a half width of $10^{\circ}$ which decays latitudinally from the equator (see Matthes et al. [2010] for details). Full vertical relaxation extends from 86 to $4 \mathrm{hPa}$ with a time constant of 10 days. The equatorial QBO forcing time series in CESM is determined from the climatology of 1953-2004 reconstructed from combined radiosonde [Naujokat, 1986] and rocketsonde measurements [Gray et al., 2001]. Further information on the QBO climatology used in our experiments can be found at http://www.pa.op.dlr.de/CCMVal/Forcings/qbo_data_ccmval/ u_profile_195301-200412.html. The filtered spectral decomposition of the climatology gives a set of Fourier coefficients that can be expanded for any day and year in the past and the future. The POP ocean module has a tripolar horizontal grid of $1^{\circ} \times 1^{\circ}$ and 60 depth levels. All analyses shown in this study were performed using the model averaged daily output.

For validation, the model results were compared with those obtained from ERA-Interim reanalysis over the period 1979-2013 [Dee et al., 2011]. ERA-Interim data are distributed on 37 pressure levels from 1000 to $1 \mathrm{hPa}$, with a vertical resolution of approximately $3 \mathrm{~km}$ in the stratosphere.

\subsection{Experimental Setup}

To assess the influence of internal variability sources (QBO) and anthropogenic forcing (greenhouse gas (GHG)/ozone-depleting substances (ODSs)) on FrlAC occurrences, we performed three sensitivity experiments which are listed in Table 1. All experiments span 145 years, starting in January 1955 and running until the end of December 2099. The reference experiment—named Natural—simulates climate natural variability in the absence of anthropogenic-induced climate change and ozone depletion (and recovery). This is achieved by keeping the GHG and ODS concentrations constant at the 1960s level. The Natural experiment is externally forced by daily reconstructed spectrally resolved solar irradiance [Lean et al., 2005] from 1955 to 2009 and by repeating twice the last four solar cycles from 2010 to 2099 . The three major volcanic eruptions observed, i.e., Agung (1963), El Chichòn (1982), and Mount Pinatubo (1991), are included by prescribing the volcanic forcing described in Stratosphere-troposphere Processes And their Role in Climate (SPARC) [2010]. The QBO is nudged between $22^{\circ} \mathrm{S}$ and $22^{\circ} \mathrm{N}$ as described in Matthes et al. [2010] and Hansen et al. [2013] and extended into the future by projecting Fourier coefficients of the oscillation.

The RCP85 and NoQBO sensitivity experiments were designed by modifying specific settings of the Natural experiment (see also Hansen et al. [2014] for a thorough description of the experiments). The RCP85 experiment differs from the Natural one in that the observed GHG and ODS concentrations are prescribed until 2005 and the RCP8.5 scenario [Meinshausen et al., 2011] is included from 2006 onward. In the NoQBO experiment, the relaxation of the equatorial winds toward observations is switched off, leading to a weak easterly climatological stratospheric tropical flow. Hence, comparing the RCP85 and NoQBO experiments with the Natural experiment allows us to quantify the influence of anthropogenic forcing and QBO, respectively, on springtime dynamical transition in the Northern Hemisphere middle polar stratosphere.

\section{FrIAC Detection}

In this section, we describe the algorithm developed to detect FrIACs and apply it to reanalysis and our model results. This new algorithm consists in a combination of previous methods described in Allen et al. [2013] and Thiéblemont et al. [2013]. In brief, we detect FrlACs by merging the anticyclone detection algorithm, used in 
Allen et al. [2013] to characterize the $2011 \mathrm{FrIAC}$, to the anticyclone/low-latitude air masses colocation method of Thiéblemont et al. [2013]. Note that the detection method of Thiéblemont et al. [2013] was not applicable here since it requires a higher horizontal stratospheric resolution than the CESM(WACCM) model allows.

\subsection{FrIAC Signatures Detection Algorithm}

FrIACs are characterized by low-latitude air masses-typically tropical/subtropical-trapped in a traveling anticyclone in the polar region. The algorithm developed to identify FrlACs is based on the detection of colocated low-latitude intrusions and anticyclonic eddies following the onset of the dynamical springtime transition in the polar stratosphere. The dynamical springtime transition corresponds to the date when high-latitude westerlies turn irreversibly to the summer easterlies. This date, hereafter referred to as "turnover," is defined as the day when the zonal mean zonal wind at $10 \mathrm{hPa}$ and $60^{\circ} \mathrm{N}$ becomes irreversibly easterly. Although several definitions of the spring dynamical transition have been proposed in the literature [e.g., Wei et al., 2007], the one selected here is particularly relevant for FrlAC detection since their persistence is modulated by the background wind and favored by summer easterlies [e.g., Allen et al., 2011].

The latitudinal origin of the air masses and their transport are diagnosed by calculating the potential vorticity (PV),

$$
\mathrm{PV}=-g(\zeta+f) \frac{\partial \theta}{\partial p}
$$

where $g$ is the gravitational acceleration, $\zeta$ the relative vorticity, $f$ the planetary vorticity, $\theta$ the potential temperature, and $p$ the pressure. The PV field is first calculated on pressure levels and then vertically interpolated on isentropic surfaces. Since the PV is conserved under frictionless and adiabatic transport [e.g., Haynes and McIntyre, 1990], it constitutes a useful tracer to examine stratospheric isentropic transport. The PV distribution on isentropic surfaces has a strong interannual variability, however, making it difficult to define a single threshold value to characterize low-latitude air masses. Hence, we converted the PV into equivalent latitude (PVEL) which is defined as the latitude of a circle centered about the pole enclosing the same area as the PV contour [Butchart and Remsberg, 1986]. If $A(P V)$ is the area enclosed by the PV contour, its PVEL is given by

$$
\operatorname{PVEL}(\mathrm{PV})=\sin ^{-1}\left(\frac{A(\mathrm{PV})}{2 \pi a^{2}}-1\right)
$$

where $a$ is the Earth's radius. We consider that low-latitude intrusions, which potentially correspond to FrIAC signatures, occur in the polar region when air masses with PVEL values lower than $40^{\circ} \mathrm{N}$ are detected northward of the $60^{\circ} \mathrm{N}$ latitude circle. Note that due to the influence of diabatic heating/cooling on PV, the PVEL cannot be considered as a passive tracer [Allen and Nakamura, 2003], particularly in the upper stratosphere in spring and summer where diabatic effects are strong. Consequently, the shape evolution and whole life cycle of FrIACs cannot be characterized using PVEL. The use of PVEL is, however, relevant to follow the early stages of FrlAC development (i.e., spin-up and "anticyclonic" phases [Allen et al., 2011, 2013]) and is thus sufficient to identify them.

Figure 1a shows the ERA-Interim PVEL field at the $850 \mathrm{~K}$ isentropic level on 10 April 2011 (or modified Julian day 100). Two distinct structures appear northward of $60^{\circ} \mathrm{N}$ : the $2011 \mathrm{FrlAC}$ characterized by anomalous lowlatitude air masses (blue) enclosed in the area centered over North America and the main fragment of the polar vortex characterized by high-latitude PVEL values located over northern Eurasia. The low-latitude air mass filament wrapped around the east edge of the vortex fragment corresponds to a remnant of the large-scale wave breaking which induced the FrIAC development.

To identify the presence of a FrIAC signature, we additionally require the low-latitude intrusion to be embedded in an anticyclone. The detection and definition of anticyclones is based on the anticyclonic edge detection algorithm described in Harvey et al. [2002] and recently used by Allen et al. [2013] to examine the evolution of the 2011 FrlAC. This algorithm uses the $Q$ scalar quantity, a measure of the relative contribution of strain and rotation on the horizontal wind field [Haynes, 1990; Fairlie, 1995], which is defined by

$$
Q=\frac{1}{2}\left(\frac{1}{a \cos \phi} \frac{\mathrm{d} u}{\mathrm{~d} \lambda}-\frac{v}{a} \tan \phi\right)^{2}+\frac{1}{2}\left(\frac{1}{a} \frac{\mathrm{d} v}{\mathrm{~d} \phi}\right)^{2}+\left(\frac{1}{a^{2} \cos \phi} \frac{\mathrm{d} u}{\mathrm{~d} \phi} \frac{\mathrm{d} v}{\mathrm{~d} \lambda}+\frac{u \tan \phi}{a^{2}} \frac{\mathrm{d} u}{\mathrm{~d} \phi}\right)
$$

where $u$ and $v$ are the zonal and meridional wind components, $\lambda$ and $\phi$ are the longitude and latitude, and $a$ is the Earth's radius. $Q$ is positive (negative) where strain (rotation) dominates the flow. Stable rotational flows 


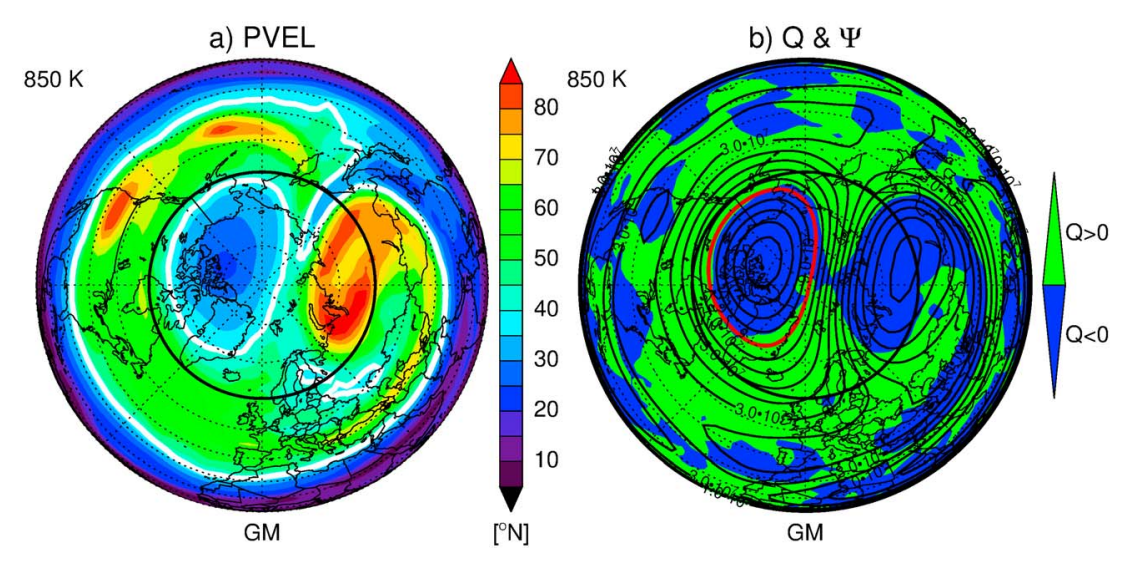

Figure 1. Northern Hemisphere (a) PVEL and (b) $Q$ quantity and stream function at $850 \mathrm{~K}$ potential temperature level for 10 April 2011. In Figure 1a the thick white line denotes the $40^{\circ} \mathrm{N}$ PVEL contours. In Figure $1 \mathrm{~b}$ black contours show stream function at regular intervals of $10^{7} \mathrm{~m}^{2} \mathrm{~s}^{-1}$. The blue (green) filled contours indicate regions of negative (positive) values of $Q$. The red contour denotes the streamline corresponding to the anticyclone edge. All quantities are calculated from ERA-Interim.

are associated with negative $Q$, typically inside vortices, while outside vortices and in the shear zones, strain dominates and $Q$ becomes positive. Integrating $Q$ around streamlines can therefore provide an objective determination of the anticyclone edge defined by the streamline where the line integral of $Q$ changes sign.

Figure $1 \mathrm{~b}$ shows the $Q$ field (color shading) and the stream function $\Psi$ (contours) at $850 \mathrm{~K}$ on 10 April 2011. The two areas, which are dominated by a coherent rotational flow and are centered over northern Eurasia (vortex fragment) and northern America (FrlAC), show negative $Q$ values (blue). The $Q$ line integrations along the streamlines are calculated with a regular increment of $10^{7} \mathrm{~m}^{2} \mathrm{~s}^{-1}$ starting from the higher value of $\Psi$, which is in this case located in the center of the FrIAC. When the integral becomes positive, the edge of the anticyclone is reached as indicated by the red contour.

A FrIAC signature is finally recorded if the ratio

$$
\frac{S_{\text {intrusion }}}{S_{\text {anticyclone }}} \times 100>b
$$

where $S_{\text {intrusion }}$ is the surface area of the low-latitude air mass intrusion enclosed in the anticyclone, $S_{\text {anticyclone }}$ is the surface area of the anticyclone (defined by the red contour), and $b$ is a dimensionless ratio threshold value expressed in percent which can be defined in the range $[0 \%, 100 \%]$. If the ratio threshold value $b$ is set to $10 \%$, equation (4) simply means that a FrIAC signature will be recorded if at least $10 \%$ of the low-latitude intrusion covers the anticyclone surface area in the polar region (northward of $60^{\circ} \mathrm{N}$ ). For the example shown in Figure 1, the anticyclonic anomaly fully contains low-latitude air masses so that the

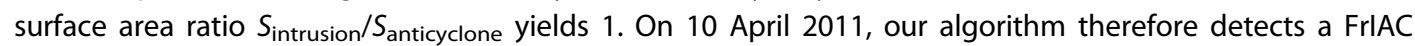
signature for any value of $b$ up to $100 \%$.

\subsection{FrIAC Representation in the Model}

We now apply our FrIAC signature detection algorithm to the three CESM(WACCM) experiments and the ERA-Interim data set for comparison. Figure 2 shows the development and life cycle of a FrlAC event simulated by the model in the RCP85 experiment for the model year 1979. On 27 March, a large-scale anticyclone enclosing low-latitude air masses of subtropical origin (PVEL $\left.<40^{\circ} \mathrm{N}\right)$ develops over east Eurasia on the southeast edge of the polar vortex (PVEL $>70^{\circ} \mathrm{N}$ ). This anticyclone is progressively advected northward, leading to a weakening and southward displacement of the polar vortex along the $90^{\circ} \mathrm{E}$ meridian (not shown). On 11 April, the FrIAC is located over northwestern America. Simultaneously, on the eastern flank of the polar vortex fragment, now located over northeastern Europe, a wave-breaking event is initiated. This wave breaking leads to the intrusion of low-latitude air masses in the polar region, which develops anticyclonically and merges with the already established FrIAC (not shown). This results in the complete disruption of the polar vortex, as revealed by the high PVEL midlatitude filaments on the map of 16 April, and the spatial expansion of the FrIAC. One month later (16 May), the FrlAC still 
a) 27 March 1979

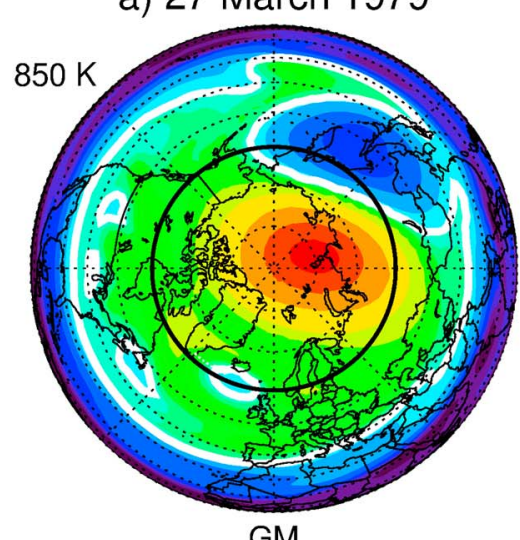

c) 16 April 1979

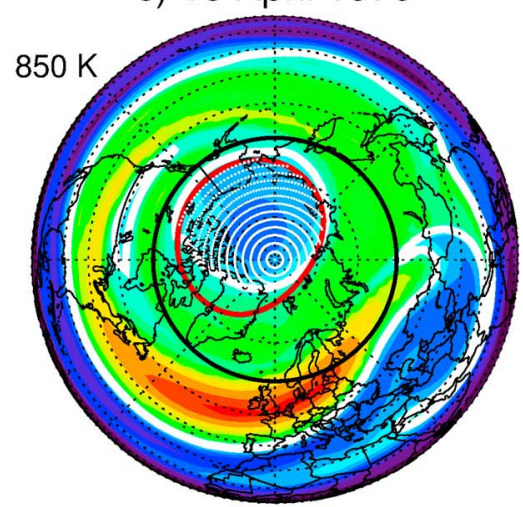

GM b) 11 April 1979

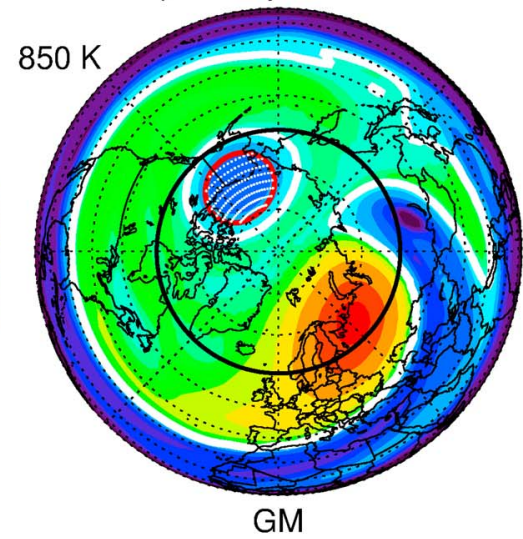

d) 16 May 1979

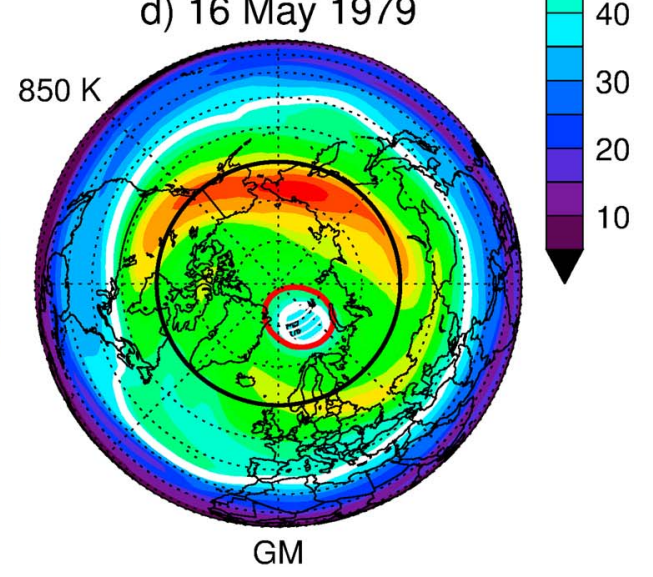
10
PVEL [ $\left.{ }^{\circ} \mathrm{N}\right]$

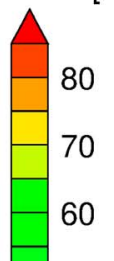

50 40

Figure 2. Northern Hemisphere PVEL (filled contour) at $850 \mathrm{~K}$ potential temperature level for selected dates of spring 1979 in the RCP85 experiment. The red contour denotes the streamline corresponding to the anticyclone edge. The dotted area indicates the region where a FrIAC is detected.

persists, although its signature is considerably weaker due to diabatic processes [Allen et al., 2013]. By this example, we show that CESM(WACCM) is able to simulate FrIAC events.

To confirm that a FrIAC event occurred in spring, the detection of a FrlAC signature in the polar region, given by equation (4), should persist for several consecutive days. By setting the ratio threshold value $b$ to $10 \%$ and given that the surface area ratio $S_{\text {intrusion }} / S_{\text {anticyclone }}$ is equal to $1,0.8$, and 0.4 on 11 April, 16 April, and 16 May 16 (Figures 2b-2d), respectively, the signature of the FrlAC simulated in spring 1979 in the RCP85 experiment is recorded for a period longer than a month. Nevertheless, the persistence of FrIACs varies highly from one event to another, depending for example on the onset of the FrIAC and the prevalence of the diabatic processes in this period of the year that act to decay the signature in the dynamical fields. FrIAC signature persistence can also depend on the spatial extent and latitudinal origin of the initial intrusion. Moreover, the detection of FrIACs is sensitive to the parameters defined in the algorithm, namely, the ratio threshold value $b$ and the number of consecutive days we require for a FrIAC to be recorded. To validate our algorithm, we performed several sensitivity tests with various values for both parameters, and we compared the results with those of Thiéblemont et al. [2013]. We recall that to classify an event as a FrlAC, Thiéblemont et al. required the centers of both the low-latitude intrusion (defined as the location of the PVEL minimum in the polar region) and the anticyclonic eddy (defined as the geopotential height maximum in the polar region) to be colocated; i.e., the distance between the two centers should be less than $1000 \mathrm{~km}$ (see Thiéblemont et al. [2013] for details). In addition, they required this colocation to persist until at least the mean date of the shearing phase (15 May).

Figure 3 shows the occurrences (in days) after the turnover where FrIACs are detected in ERA-Interim by the algorithm with the ratio threshold value $b$ set to $10 \%$ and the number of consecutive days to 20 . The stars 


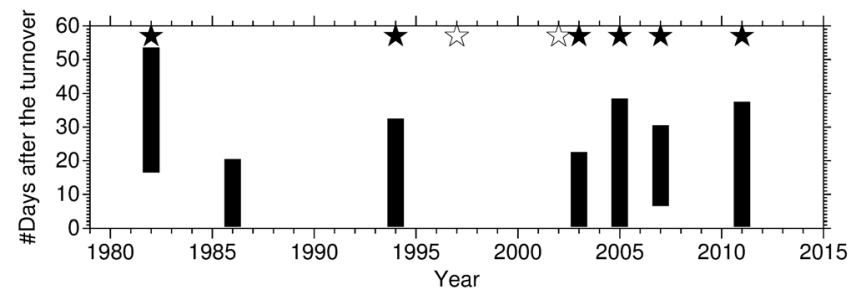

Figure 3. FrIAC events detected (see text for details) within 60 days after the turnover for each spring from 1979 to 2013 using ERA-Interim. The stars show the FrIACs recorded in Thiéblemont et al. [2013] (filled stars indicate the strongest FrIAC cases).

recorded, with a particularly weak low-latitude air mass signature and with a small spatial extent. As a result neither of these two FrIACs was sufficiently strong to be detected with our algorithm in the chosen setting. The 1986 event was also discussed in Thiéblemont et al. [2013] but not retained as a FrlAC since its signature in the polar region was removed before the shearing phase. The dynamical conditions and developing stages of the 1986 event (i.e., the focus of the present study) were nevertheless very similar to the other recorded FrIACs. These few discrepancies between the two studies reflect the fact that there is no unique way to describe slightly different phenomena of the same nature. Nevertheless, with these parameter settings, our new algorithm is able to capture the strongest FrIACs that have been unambiguously detected in previous studies [Allen et al., 2012; Thiéblemont et al., 2013]. The sensitivity tests (not shown) further revealed that the number of FrlAC cases recorded was only weakly sensitive to the ratio threshold value $b$ and the number of consecutive days so that the results of the composite analysis thereafter were negligibly affected.

Now that the different parameters of the algorithm have been validated using ERA-Interim, we examined the three different CESM(WACCM) experiments over the full simulation period. Results are shown in Figure 4. Over the period 1955-2099, 19, 20, and 27 turnovers with FrlAC events were detected in the Natural, RCP85, and NoQBO experiments, respectively. Similarly to the ERA-Interim analysis (Figure 3), FrIAC events simulated by the model showed a broad range of persistence between 20 (i.e., detection limit) and 40 days. Note, for instance, that the 1979 FrIAC of the RCP85 experiment described previously (Figure 2) was recorded 40 consecutive days by our algorithm.

As mentioned above, the ERA-Interim data set used here spans 35 years and the CESM(WACCM) simulations span 145 years each. The FrIAC/turnover ratio yields $0.20,0.13,0.14$, and 0.19 for ERA-Interim, the Natural experiment, RCP85 experiment, and NoQBO experiment, respectively. According to a $\chi^{2}$ test, we found that the higher FrIAC/turnover ratio in ERA-Interim compared to the Natural experiment is not statistically significant. Although this statistical test is sensitive to the limited number of years in ERA-Interim, these results demonstrate that the CESM(WACCM) model can simulate a credible FrIAC occurrence frequency.

A noticeable difference appears in the NoQBO experiment which shows markedly more FrIAC events than the other two experiments when the same extended time period is considered. As suggested in previous studies [Thiéblemont et al., 2011, 2013], our model results similarly show that the QBO might influence FrlAC occurrences. The influence of $\mathrm{QBO}$ on FrIACs will be further discussed in sections 5 and 6 . We additionally note that no future trend in FrIAC occurrence (Figure 4) is found when a strong global warming scenario is prescribed in the model (i.e., RCP85 experiment). In the three experiments, however, there appear to be groups of years in which there are several FrlACs recorded in a limited time period (e.g., 1970s and 2070s in the Natural experiment) and, conversely, also long periods (>10years) with no FrlACs (e.g., 2080-2099 in the Natural experiment or the 1990s in the RCP85 experiment). Therefore, the increased FrlACs frequency observed in 2000-2011 [Thiéblemont et al., 2013] may be one of these types of periods rather than what originally was interpreted to be a trend.

Our analysis of FrIAC frequency in CESM(WACCM) reveals that the model can simulate a substantial number of FrIACs of various persistence consistent with reanalysis. To investigate the dynamics associated with FrIAC events, we then performed a composite analysis based on springs in which FrlAC events were detected. The FrlAC composites are based on 19, 20, and 27 springs (out of 145) for the Natural, RCP85, and NoQBO experiments, respectively. The statistical significance levels of the composite analysis are estimated using a 

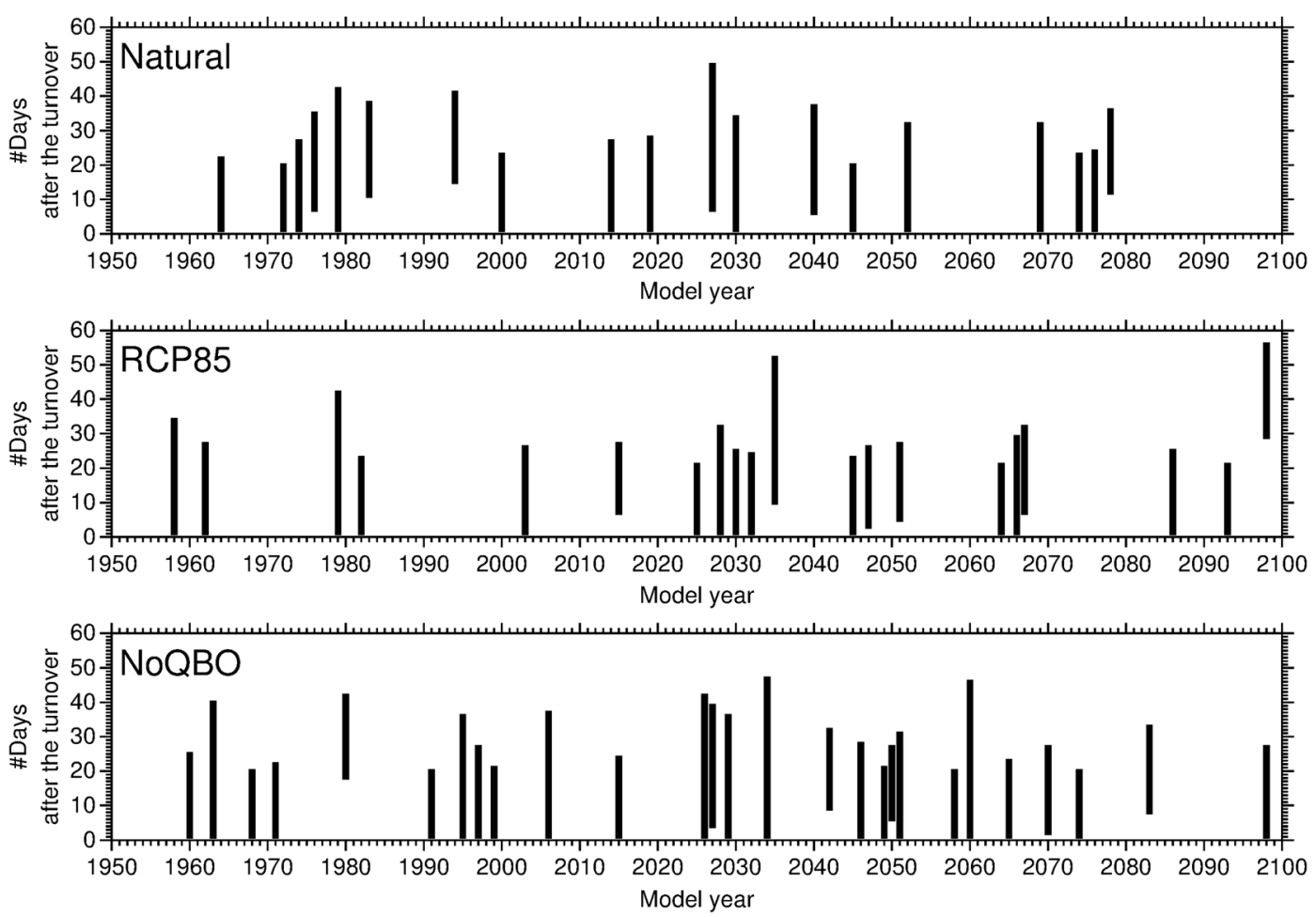

Figure 4. As Figure 3 but for the Natural, RCP85, and NoQBO model experiments.

bootstrapping technique with replacement. The procedure is to select a random subset from the original time-dependent data set with the number of samples equal to the original composite subset. This procedure is repeated 1000 times, and a probability density function (PDF) is constructed. Finally, the PDF is used to determine the likelihood of the derived signals to arise by chance. For two dimensional fields, the procedure is repeated for each grid point. Two-tailed tests are used.

\section{Stratosphere Dynamics Associated With FrlACs}

We first examine the turnover onset associated to FrIAC events. Figure 5 shows the climatology of the turnover date for the reanalysis and the three different experiments. In the reanalysis the average turnover date is on day 110 ( 20 April). In the model, the mean date of the turnover is delayed by more than 6 days compared to the reanalysis. This difference is statistically significant ( $p$ value $<0.05$ ) and is consistent with the wellknown cold vortex bias in this version of CESM(WACCM) [Marsh et al., 2013]. Changing the model setting does not significantly affect the turnover date which is roughly constant between the three experiments. As shown in Figure 5, FrlACs occur under anomalously early turnovers in the reanalysis and the model. In the reanalysis,

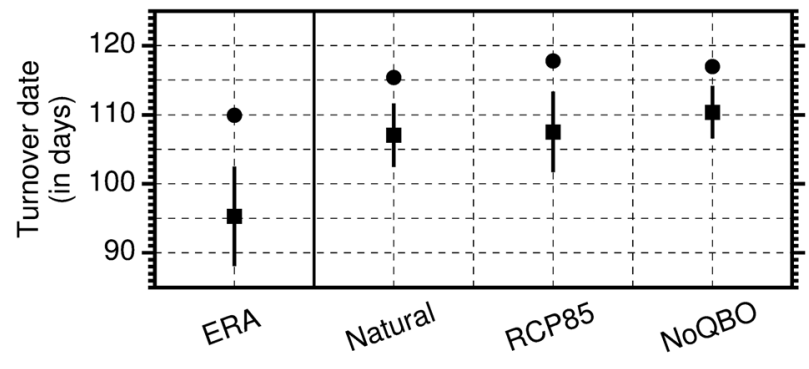

Figure 5. Climatological (dots) and FrIAC years (squares) averaged turnover date (in number of days after 1 January) calculated for the reanalysis and the three model experiments. Bars indicate the $2 \sigma$ confidence interval.
FrlACs are associated with turnovers which occur on average 15 days ahead of the climatological date. In the model, the FrIAC associated turnovers occur significantly earlier than the climatology by 8,10 , and 6 days in the Natural, RCP85, and NoQBO experiments, respectively.

Figure 6 shows composite anomalies (FrlAC years minus all years) of the high-latitude zonal mean circulation (Figure 6a) and planetary wave activity (Figures $6 \mathrm{~b}$ and $6 \mathrm{c}$ ) in the 


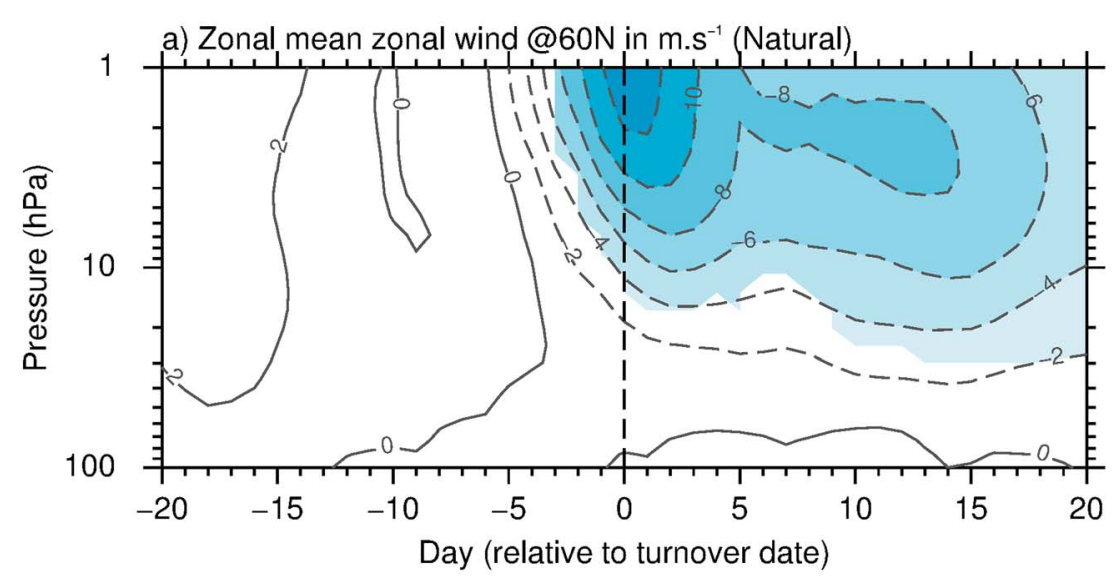

b) Meridional eddy heat flux $\left(40-80^{\circ} \mathrm{N}, 30 \mathrm{hPa}\right)$

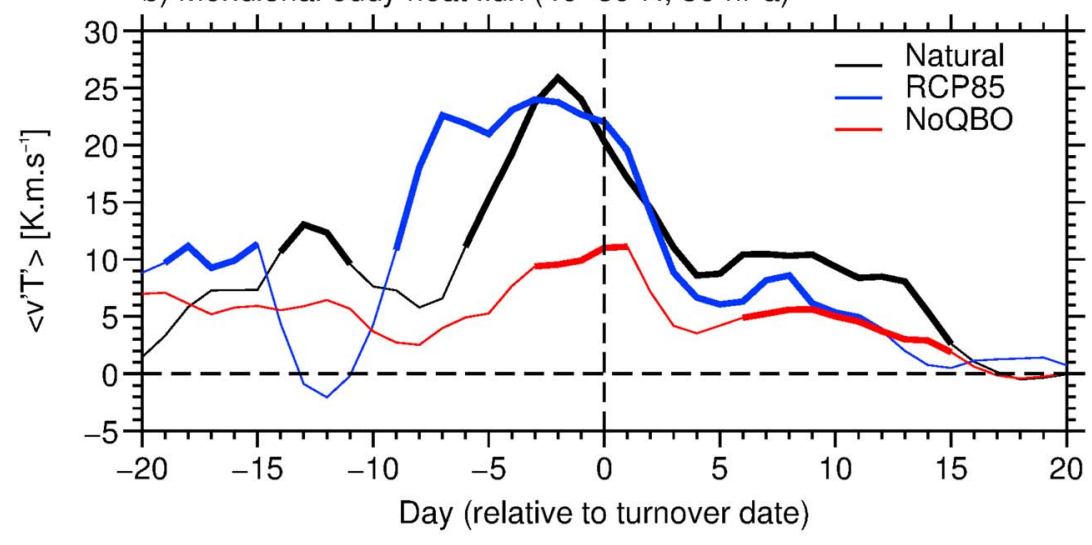

c) Meridional eddy heat flux $\left(40-80^{\circ} \mathrm{N}, 100 \mathrm{hPa}\right)$

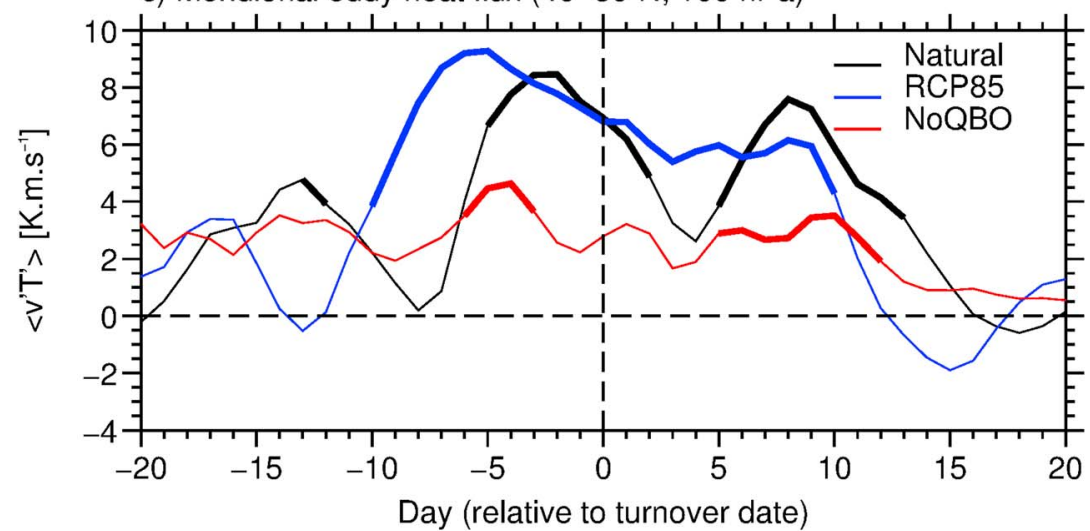

Figure 6. Difference FrIAC years minus all years, from -20 to 20 days around the turnover date, of the deseasonalized (a) zonal mean zonal wind at $60^{\circ} \mathrm{N}$ as a function of pressure level (in $\mathrm{hPa}$ ) for the Natural experiment; (b) meridional eddy heat flux at $30 \mathrm{hPa}, 40-80^{\circ} \mathrm{N}$ for all experiments; and (c) meridional eddy heat flux at $100 \mathrm{hPa}, 40-80^{\circ} \mathrm{N}$ for all experiments. In Figure 6a positive (solid) and negative (dashed) contours are drawn every $2 \mathrm{~m} \mathrm{~s}^{-1}$. Shading (Figure 6a) and thicker segments (Figures $6 \mathrm{~b}$ and $6 \mathrm{c}$ ) indicate that the FrIAC anomalies are significantly different from the climatological anomalies at the $95 \%$ confidence level.

stratosphere, around the turnover onset. Note that time series of zonal mean zonal wind and meridional eddy heat flux have all been deseasonalized beforehand by subtracting the daily climatology derived as the daily average of all years. This allows reducing the seasonal influence on signals which may arise since FrlACs occur under anomalous early turnover. The early turnover associated with FrIAC events is associated with an 

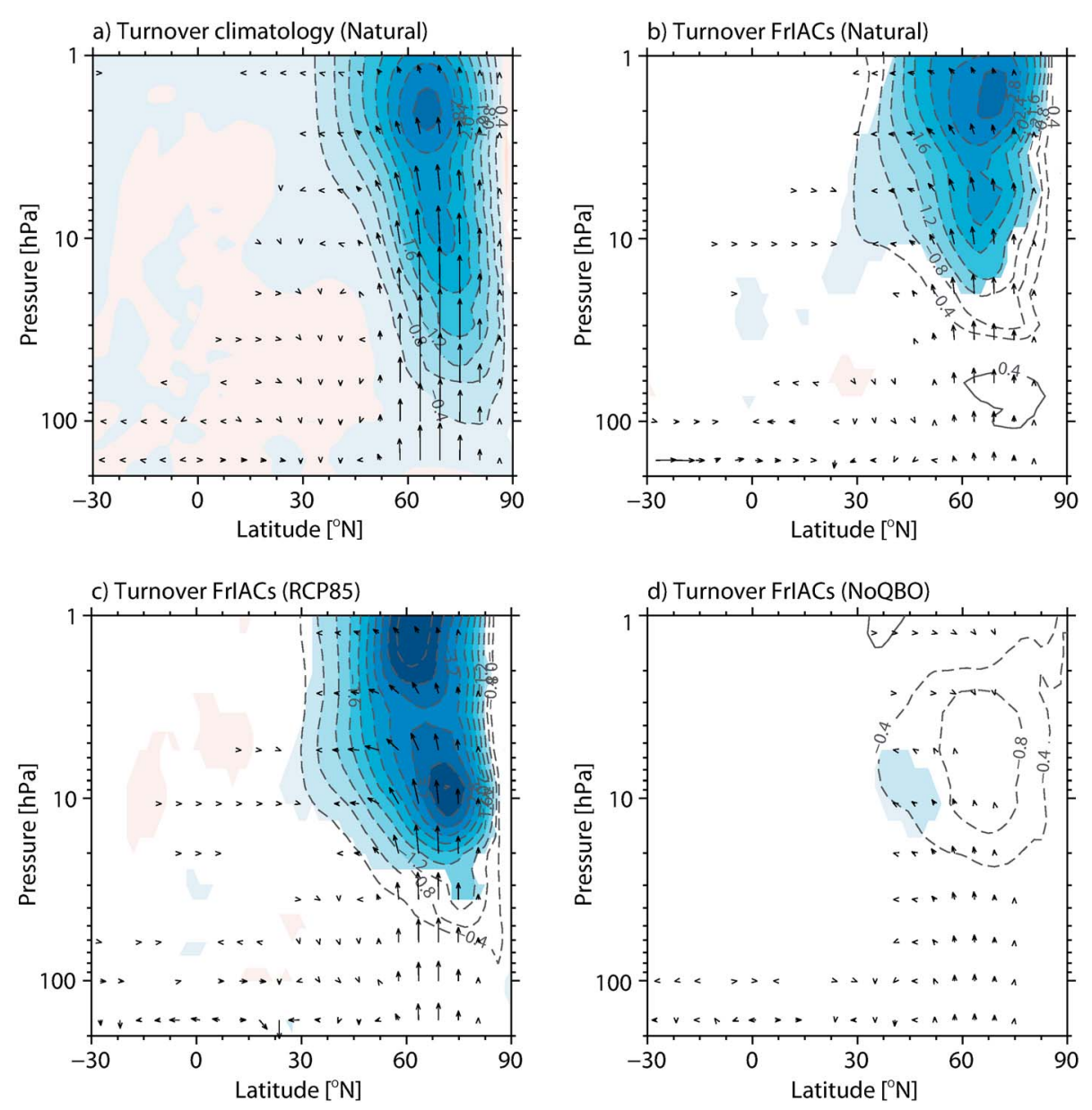

Figure 7. (a) Turnover anomalies (for all years), averaged from - 10 days to the turnover date, of the Eliassen-Palm flux (vectors) and its divergence (contours) in the Natural experiment (see text for details). Difference FrlAC years minus all years of the turnover anomalies for the (b) Natural, (c) RCP85, and (d) NoQBO experiments. Contours are drawn every $0.4 \mathrm{~m} / \mathrm{s} / \mathrm{d}$. Dashed (solid) contours indicate relative convergence (divergence). Shading indicates that the turnover anomaly associated with FrlACs is statistically significantly different at the $95 \%$ confidence level from the one derived with all turnovers.

intense zonal circulation reversal at $60^{\circ} \mathrm{N}$ which expands in the upper and middle stratosphere from the stratopause region $(1 \mathrm{hPa}$ ) down to $\sim 20 \mathrm{hPa}$ (Figure 6a). Although the polar vortex is neither particularly strong nor weak before the turnover, the postturnover easterlies are significantly stronger than the deaseasonalized climatology with an anomaly of at least $-4 \mathrm{~m} / \mathrm{s}$ which persists for several weeks. This intense wind reversal, also found in the RCP85 and NoQBO experiment (not shown for brevity), is due to significantly enhanced planetary wave activity entering the stratosphere associated with FrlAC turnover, as shown by the strong positive eddy heat flux anomalies calculated at midlatitudes, $30 \mathrm{hPa}$ (Figure 6b) and $100 \mathrm{hPa}$ (Figure 6c). Note that for the NoQBO experiment, this anomaly is markedly weaker than for the two remaining experiments and only marginally significant. Interestingly, it is also the experiment with the highest FrIAC frequency. Hence, wave activity is not the only factor favoring the occurrence of FrIACs; the dynamical state of the flow in the tropical region might also modulate them (see also sections 5 and 6).

Figure 7a shows the wave activity (Eliassen-Palm flux or EP flux) and wave-mean flow interaction (EP flux divergence) mean anomalies preceding the turnovers in the Natural experiment. The mean anomaly for both quantities refers to the daily mean absolute deviation from climatology, averaged from days -10 to 0 relative to the turnover and for all turnovers ( 145 cases). The climatology is calculated using the 10 days preceding the turnover for all 145 years of the simulation. The turnovers are overall associated with enhanced wave activity penetrating the stratosphere around $60^{\circ} \mathrm{N}$ which induces increased wave breaking above $30 \mathrm{hPa}$ as 
revealed by the anomalous EP flux convergence. As these features are very similar for the RCP85 and the NoQBO experiments, figures are not shown for brevity. To investigate the wave-induced anomalies associated with FrIACs, we calculated EP flux and EP flux divergence differences (averaged over 10 days before the turnover) between FrlAC years and all years. Results are shown on Figures $7 b-7 d$ for the Natural, RCP85, and NoQBO experiments, respectively. The RCP85 and Natural experiments show comparable anomalies with increasing wave activity in the stratosphere around $65^{\circ} \mathrm{N}$ and statistically significant EP flux convergence anomalies above $30 \mathrm{hPa}$. Hence, the wave forcing anomaly associated with FrlAC turnovers (Figures 7b-7d) is amplified compared to the mean anomaly (shown in Figure 7a). For the RCP85 experiment, the anomalies are slightly more pronounced, however, and show two distinct maxima centered at $10 \mathrm{hPa}$ and $2 \mathrm{hPa}$. For the Natural experiment, one distinct maximum is found at $2 \mathrm{hPa}$. The main differences appear for the NoQBO experiment where the signal is qualitatively consistent with the Natural and RCP85 experiments but considerably weaker in magnitude and only marginally significant at $10 \mathrm{hPa}$. The NoQBO experiment EP flux diagnostic anomalies are consistent with the reduced eddy heat flux anomalies found in Figure 6.

These results, hence, demonstrate that FrIAC events are generally associated with enhanced planetary wave propagation and breaking during the springtime dynamical transition which occurs anomalously early and which is associated with a strong and abrupt zonal wind reversal. The experiment without QBO nudging shows markedly different features, however; despite the significant frequency increase of FrIAC events in this experiment, the strength of the associated planetary wave forcing is strongly reduced. It therefore suggests that the development of FrIACs may be influenced by some particular dynamical preconditioning in the stratosphere that we examine in the following section.

\section{Stratospheric Dynamical Preconditioning}

In the previous studies by Thiéblemont et al. [2011, 2013], it was suggested that the absence of stratospheric major warmings during winter, as well as an easterly zonal wind regime in the tropical stratosphere, could favor FrIAC occurrences in spring. These findings were, however, based on a restricted number of observed events which made their statistical representativeness difficult to estimate. Since we have shown above that FrIAC events and their associated dynamical mechanisms are adequately reproduced in CESM(WACCM) and given the extended simulated FrIAC sample (i.e., 435 model years including 66 with FrlACs), we propose to further examine the influence of $\mathrm{mSSWs}$ and QBO on FrIAC occurrences.

\subsection{Influence of mSSWs on FrIAC Occurrences}

The sensitivity of mSSW detection to the particular definition used to identify them was recently addressed by Butler et al. [2015]. Since no consensus on an optimal definition of mSSWs has been reached yet, we chose to follow the definition used in the recent study by Hansen et al. [2014] where some periods of the same CESM(WACCM) sensitivity experiments were investigated. Major SSWs are identified by the simultaneous reversal of the zonal mean zonal wind at $10 \mathrm{hPa}$ and $60^{\circ} \mathrm{N}$ and the zonal mean temperature difference between $60^{\circ} \mathrm{N}$ and the pole [Labitzke, 1981]. The winter season is defined from 1 November to 15 days before the turnover date in order to avoid any overlap between the SFW and mSSWs.

Figure 8 shows the probability that at least one mSSW occurred during winter when all the model years are considered (colored bars) and when only the FrIAC years are considered (gray bars). The Natural and RCP85 experiments show frequencies of $38 \%$ and $40 \%$ of winters where at least one mSSW occurred, respectively, when all years are considered. Note that these frequencies are slightly lower than in the study by Hansen et al. [2014] (41\% for both experiments), since in our case winters with more than one mSSW count only for one. In the NOQBO experiment the frequency significantly increases up to $52 \%$. This increased frequency in the NoQBO compared to the Natural and RCP85 experiments is statistically significant at the $5 \%$ level according to a $\chi^{2}$ test. These results confirm those of Hansen et al. [2014], although their NoQBO experiment was only 56 years long. They found that when the QBO nudging is switched off and equatorial winds are in permanent easterly phase (as in the NoQBO experiment), the polar night jet decelerates through wave-mean flow interaction; thus, the polar vortex is weaker allowing more mSSWs to occur. If we now consider only years when FrlACs occurred in spring (gray bars), the frequency of winters with mSSWs significantly drops to $16 \%, 30 \%$, $15 \%$, and $19 \%$ for the Natural, RCP85, NoQBO, and all experiments, respectively. Note that in the case of the RCP85 experiment, the frequency decrease associated with FrlACs is not statistically significantly different from the one with all winters included. 


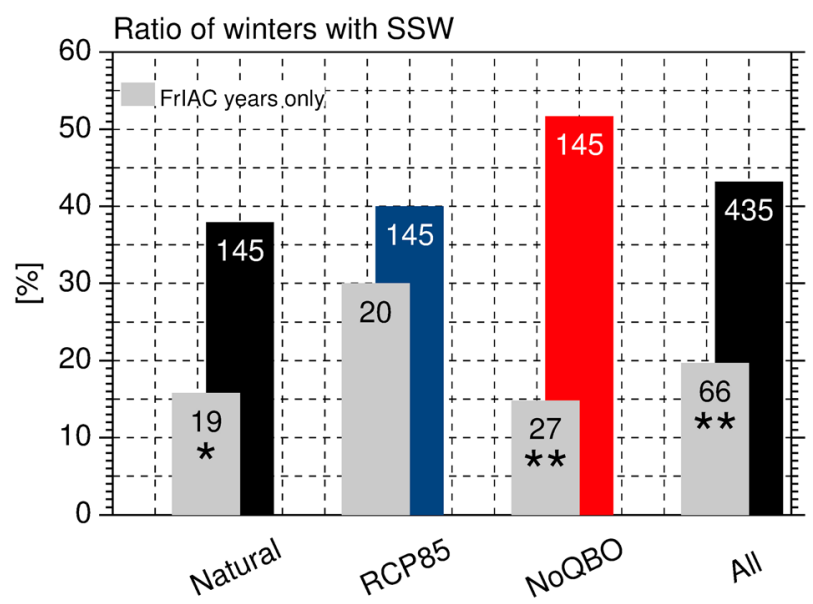

Figure 8. Probability that at least one mSSW occurs during winter when all years (colored bars) and FrIAC years only (gray bars) are considered. The results from the Natural, RCP85, and NoQBO experiments are shown in black, blue, and red, respectively. The last column shows a combination of the three experiments. The numbers on top of each histogram indicate the number of years sampled. A single (double) star indicates that the frequencies are significantly different at the $95 \%$ (99\%) level.
These results demonstrate that in our model, the occurrence of mSSWs in the previous winter reduces the likelihood of a FrIAC developing in spring, as already suggested by previous work based on reanalysis [Thiéblemont et al., 2011]. In the following, we investigate the dynamical reasons for this relationship in more detail. As the analysis of the different experiments was found to be very similar, we only show those from the Natural experiment.

Figure 9 shows the monthly climatology (dashed) and composite during winters when at least one mSSW occurs (solid), for a zonal mean zonal wind at $10 \mathrm{hPa}$ and $60^{\circ} \mathrm{N}$ (Figure 9a), at $100 \mathrm{hPa}$ and $60^{\circ} \mathrm{N}$ (Figure 9b), and the vertical component of the EP flux $(F z)$ at $60^{\circ} \mathrm{N}$ and $100 \mathrm{hPa}$ (Figure 9c). $\mathrm{Fz}$ at $100 \mathrm{hPa}$ is used to characterize the planetary wave activity entering the stratosphere. Averaged winters when mSSWs occur are associated with a weakening of the polar night jet as revealed by a reduction in the westerly winds speed by more than $5 \mathrm{~m} \mathrm{~s}^{-1}$ (Figure 9a) which remains statistically significant from January to March. In the middle stratosphere, the vortex weakening associated with mSSW winters is no longer observed in April, while in the lower polar stratosphere (Figure 9b), it persists in April. The detailed evolution of the polar vortex for individual winters naturally depends on the exact timing of the mSSWs, but this will not be further discussed here as it goes beyond the scope of the present study. As expected, the mSSW years are on average associated with increasing wave activity entering the stratosphere in early winter as revealed by the $F z$ (Figure 9c), peaking in January which corresponds to the month with the highest frequency of mSSWs (not shown). The wave activity associated with mSSW winters flips below the climatology in March and becomes statistically significantly lower in April with a magnitude reduced by $10^{4} \mathrm{~kg} \mathrm{~s}^{-2}$. Thus, the occurrence of $\mathrm{mSSWs}$ in winter leads to a persisting weaker polar vortex in the lower polar stratosphere until spring and to a significant reduction of upward wave propagation in April, which corresponds to the month when FrlACs are more likely to develop (e.g., Figure 5).

The amplitude in April of the planetary waves that are likely to propagate in the stratosphere (i.e., wave numbers 1-3) is further examined in Figure 10 where Figure 10a shows the climatology for the Natural experiment and Figure 10b shows the anomalies associated with mSSW winters. While no significant anomaly is found in the troposphere, a strong and statistically significant reduction of wave amplitude is observed in the high-latitude stratosphere developing above the $100 \mathrm{hPa}$ level. These results suggest that $\mathrm{mSSWs}$ in winter affect springtime wave propagation conditions internally to the stratosphere rather than tropospheric wave sources. This in turn leads to a modulation of FrIAC development.

Next we examine the stationary planetary wave propagation conditions using the probability density of negative refractive index squared $f\left(n_{k}^{2}<0\right)$. This analysis tool makes it possible to estimate favorable stationary planetary wave propagation conditions in specific periods at different latitudes and heights and avoids the problem of overlapping of positive and negative $n_{k}^{2}$ when performing time mean calculation, which makes the results hard to interpret. The monthly $f\left(n_{k}^{2}<0\right)$ is derived by counting, for each latitude/height grid point, the number of days with negative $n_{k}^{2}$ and dividing it by the total number of days in the month of interest (here April). An extensive discussion on the $f\left(n_{k}^{2}<0\right)$ diagnostic tool and its comparison with $n_{k}^{2}$ can be found in Li et al. [2007].

Figure 11 shows the climatology (Figure 11a) and the anomaly associated with mSSW winters (Figure 11b) of the $f\left(n_{k}^{2}<0\right)$ in April. The climatology in our Natural experiment reveals a region of enhanced $f\left(n_{k}^{2}<0\right)$ 

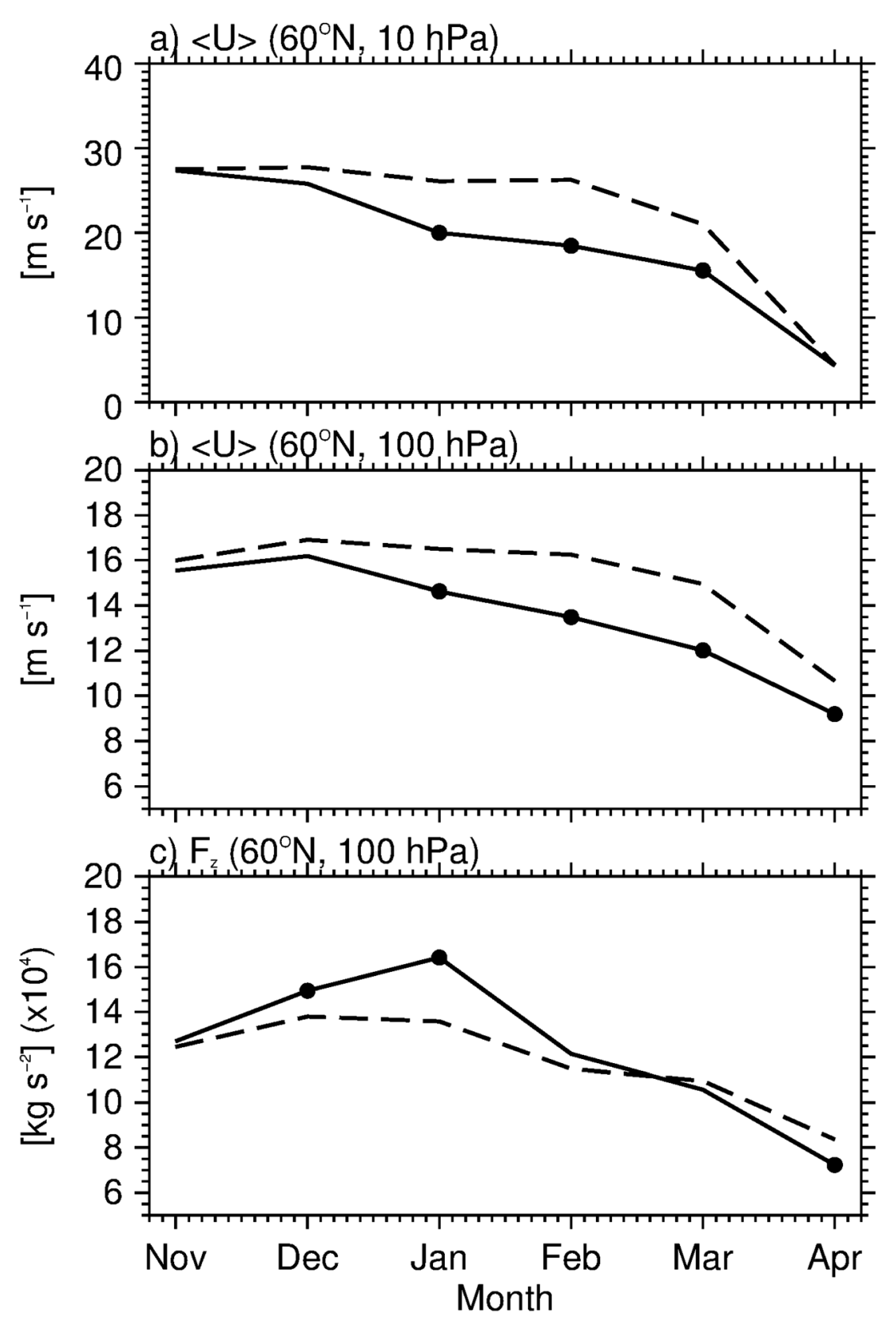

Figure 9. Composite (solid) of the (a) zonal mean zonal wind at $10 \mathrm{hPa}, 60^{\circ} \mathrm{N}$; (b) zonal mean zonal wind at $100 \mathrm{hPa}, 60^{\circ} \mathrm{N}$; and (c) the vertical component of the EP flux at $100 \mathrm{hPa}, 60^{\circ} \mathrm{N}$, in years when at least one mSSW occurred during the winter. The dashed line shows the climatology. Only results from the Natural experiment are shown. Dots indicate months when the mSSW composite is statistically different from the climatology at the $99 \%$ confidence level.

centered at $40^{\circ} \mathrm{N}$ and $70 \mathrm{hPa}$ and a layer of pronounced $f\left(n_{k}^{2}<0\right)$ at $150 \mathrm{hPa}$ and $50^{\circ} \mathrm{N}$ which increases while expanding poleward (Figure 11a). These two main features are consistent with the December-JanuaryFebruary $f\left(n_{k}^{2}<0\right)$ climatology shown in Li et al. [2007], who used NCEP/NCAR reanalyses. The anomalies associated with $\mathrm{mSSW}$ winters show negative relative frequencies at higher levels than $10 \mathrm{hPa}$ in the latitude range $40-80^{\circ} \mathrm{N}$, indicating favorable dynamical conditions for wave propagation in the upper stratosphere (Figure $11 \mathrm{~b}$ ). In contrast, the lower stratosphere at middle to high latitudes shows a clear enhancement of $f$ $\left(n_{k}^{2}<0\right)$, maximizing in a layer located just below $100 \mathrm{hPa}$ which indicates less favorable conditions for planetary waves to enter the stratosphere. These less favorable wave propagation conditions in spring after mSSW occurrences are highly consistent with the reduced probability of FrIAC development. 

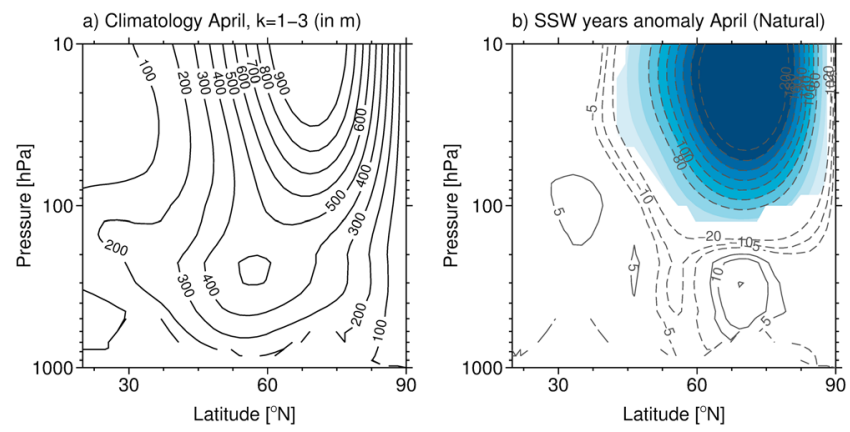

Figure 10. (a) Climatology and (b) mSSW years anomaly in April of the geopotential height wave amplitude for the planetary-scale waves (wave numbers 1-3). Contours are drawn with intervals of (a) $100 \mathrm{~m}$ and (b) $5 \mathrm{~m}$ in the $[-10,10] \mathrm{m}$ range and $10 \mathrm{~m}$ otherwise. Shading indicates regions where anomalies are statistically different from the climatology (Figure 10a) at the $95 \%$ confidence level.

These results seem to suggest that the QBO phase may significantly influence FrIAC events.

Figure 12 shows the zonal mean zonal wind anomalies associated with FrlACs averaged 10 days before the turnover onset. Only the Natural experiment results are shown since those of the RCP85 experiment are almost identical. The period preceding turnovers associated with FrIACs shows no significant zonal wind anomalies in the polar region (also consistent with Figure $6 \mathrm{a}$ ). Between $25^{\circ} \mathrm{S}$ and $25^{\circ} \mathrm{N}$ in the stratosphere, the zonal mean zonal wind shows statistically significant easterly (westerly) anomalies, which are centered at $10 \mathrm{hPa}(50 \mathrm{hPa})$ and peak by less than $-10 \mathrm{~m} \mathrm{~s}^{-1}$ (more than $5 \mathrm{~m} \mathrm{~s}^{-1}$ ). Thus, these model results, combined with the NoQBO experiment results, support the suggestion that FrIAC occurrences are favored by an easterly circulation in the tropical middle stratosphere (from $\sim 20$ to $3 \mathrm{hPa}$ ).

\section{Summary and Discussion}

In this paper, we investigated extratropical stratospheric transport and dynamical variability during springtime transitions using the CESM(WACCM) model. For the first time, we showed that a fully coupled model is able to reproduce FrlAC events which are characterized by low-latitude air masses transported to the polar region and which persist within an anticyclonic anomaly. A comparison with reanalysis reveals that persistent FrIACs are well simulated with CESM(WACCM). By comparing the different model experiments, we demonstrated that the QBO significantly modulates their frequency of occurrence, with an enhanced number of FrlACs when an easterly circulation prevails in the tropical middle stratosphere. In contrast, we found no
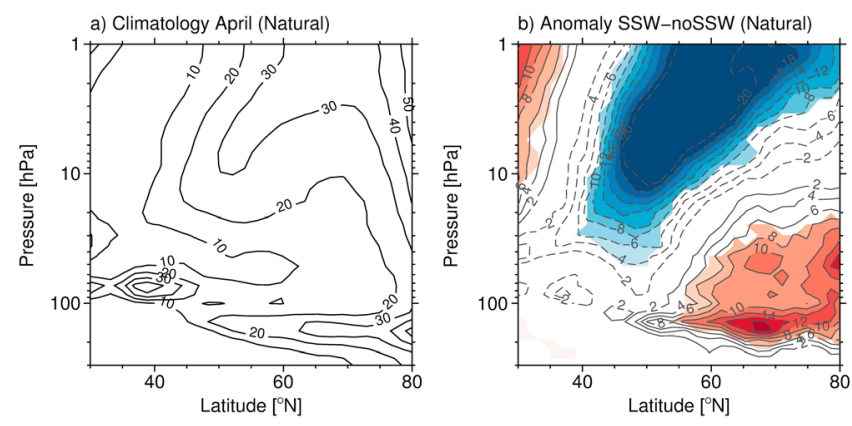

Figure 11. (a) Climatology and (b) mSSW years anomaly of the probability density of negative refractive index squared expressed in percent of days in April for the planetary-scale wave (wave number 1). Contours are drawn with intervals of $10 \%$ (Figure 11a) and 1\% (Figure 11b). Shading indicates regions where anomalies are statistically different from the climatology (Figure 11a) at the $95 \%$ confidence level. influence of anthropogenic forcing (i.e., increasing GHG concentration and varying ODS concentration) on the frequency of FrlACs when comparing the Natural and RCP85 experiments. Our model results did not reveal any trend in FrIAC occurrences in a future climate, specified by that scenario. They rather suggest the existence of near-decadal periods with increased FrIACs occurrence which may be fortuitously interpreted as a trend.

The FrlAC composite analysis revealed distinct dynamical processes leading to FrIAC development. FrIACs develop under an anomalously early and 


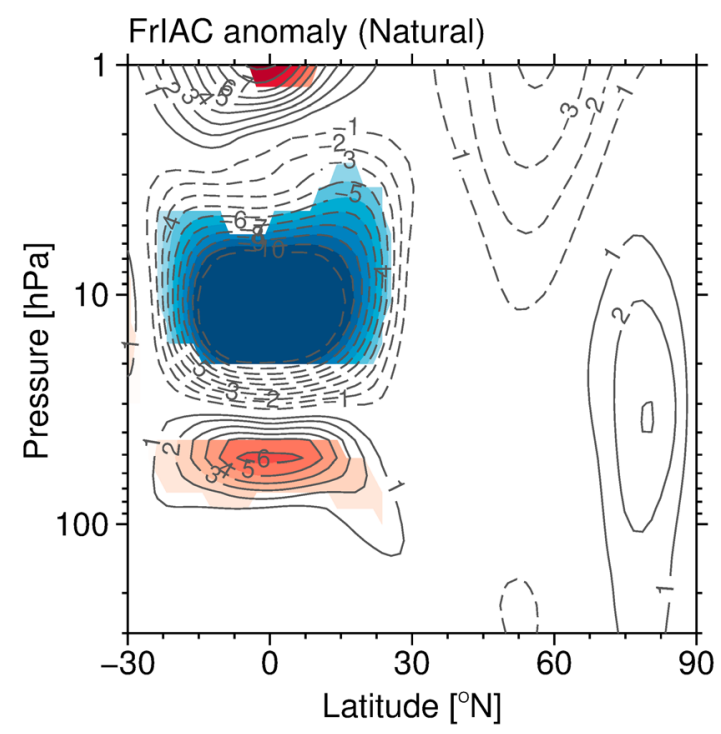

Figure 12. Anomaly of the zonal mean zonal wind averaged from -10 to 0 days before the turnover, in years, when FrIACs occur. Contours are drawn with intervals of $1 \mathrm{~m} / \mathrm{s}$. Shading indicates regions where anomalies are statistically different from the climatology at the $95 \%$ confidence level. abrupt springtime dynamical transition which is mainly driven by an enhancement of planetary wave propagation in the stratosphere and planetary wave breaking in the middle and upper high-latitude stratosphere. Given the close connection between planetary wave activity and FrlACs, the absence of trends in FrIAC occurrence in a future climate projection is not surprising since no meridional heat flux trend was found in our RCP85 experiment in late winter (not shown). These results reflect the current discrepancies in models to identify robust changes in tropospheric wave forcing induced by anthropogenic forcing [e.g., SPARC CCMVal, 2010, chapter 4].

The large sample of intense FrIACs (66 in total simulated for 435 years) was used to further test the robust-

ness of dynamical preconditions favoring FrIAC occurrences which have been suggested by previous work based on reanalysis [Thiéblemont et al., 2011, 2013], i.e., influence of winter stratospheric major warmings and of the QBO. In agreement with previous findings, we showed that FrlACs are more likely to develop in spring (i) if no mSSW occurred during the preceding winter and (ii) under an easterly zonal circulation in the tropical midstratosphere.

Regarding the influence of mSSWs, we showed that the background dynamical state alteration induced by $\mathrm{mSSW}$ in the polar region persists longer in the lower stratosphere than in the middle and upper stratosphere. The persistence of these anomalies after mSSWs leads to less favorable conditions for planetary waves to enter the high-latitude stratosphere in April, which in turn results in a lower probability of FrlAC development. This mechanism is in fact similar to the one induced by polar night jet oscillation (PJO) events [Hitchcock et al., 2013a, 2013b]. PJO events stem from particularly deep mSSWs leading to an anomalously warm polar lower stratosphere and anomalously weak lower stratosphere winds which can persist for several months after the initial warming. This extended polar vortex recovery in the lower stratosphere during PJO events is closely related to the longer radiative time scales in the lowermost stratosphere [Dickinson, 1973]. Similarly, PJO events are also associated with an extended period of suppressed wave activity flux entering the polar vortex. We further note that the relationship between PJO events in winter and absence of FrIACs in spring is well verified in the reanalysis by comparing our FrlAC signature record (Figure 3) and the abacus plots of Hitchcock et al. [2013a, Figure 4]; the springs with the strongest FrIAC signatures coincide with the absence of PJO events in winter.

Interestingly, the model experiment with permanent easterlies in the tropical stratosphere (NoQBO) revealed a statistically significant higher number of both FrIACs and mSSWs. While this supports our findings that an easterly middle stratosphere zonal circulation favors the occurrence of FrIACs (Figure 12), it may seem in contradiction with the relationship opposing FrlACs and mSSWs. Figure 8 confirms, however, that the $\mathrm{FrIAC/mSSW}$ relationship still holds in the NoQBO experiment where the probability of having both mSSW and FrIAC during the same winter/spring is significantly reduced.

One possible explanation for the larger frequency of FrIACs in the NoQBO experiment could be related to the weakening of the polar vortex induced by permanent tropical easterlies (as shown in Hansen et al. [2014] and concordant with the Holton-Tan (HT) effect [Holton and Tan, 1980, 1982]). We recall that the HT effect suggests that the vortex becomes stronger and colder (weaker and warmer) under the westerly (easterly) phase of the QBO. In the Northern Hemisphere winter, the HT effect is most apparent when the QBO definition is 
based on the equatorial zonal wind anomaly in the lower stratosphere $(\sim 50 \mathrm{hPa})$. Hence, permanent easterlies over the full range of altitudes in the tropical stratosphere may lead to an average weaker polar vortex, a potentially more permeable mixing barrier between the middle and high latitudes, and thus more FrIACs. However, although a significantly weaker polar vortex in January/February/March is found in the NoQBO experiment in comparison with the two experiments which include all sources of variability [Hansen et al., 2014], it is no longer the case in April when FrlACs are more likely to develop. Furthermore, by examining the latitudinal PV gradient, we did not find clear evidence of a more permeable mixing barrier between the middle and high latitudes in the NoQBO experiment (not shown). Hence, the potential mechanism linking the tropical zonal wind regime and vortex strength does not seem prominent to explain variations in the occurrence of FrIACs. Another striking feature of the NoQBO experiment is that FrIAC cases are associated with a significantly reduced planetary wave forcing during the turnover compared to the two remaining experiments (Figures 6 and 7). These relatively less dynamically active turnovers associated with FrlAC occurrences and the increase in FrIAC frequency suggest that the background state in the NoQBO experiment favors FrIAC development.

In the following, we discuss the possible influence of the QBO on the nature of the planetary wave breaking and FrIAC development. Knox and Harvey [2005] suggested that planetary wave breaking events in the stratosphere are modulated by the background zonal-mean zonal wind shear induced by the QBO. Furthermore, Peters and Waugh [1996] examined the geometry of poleward wave breaking events in the vicinity of the tropopause region. They showed that particular poleward wave breaking in an anticyclonic wind shear (called P2) leads to the intruding air from lower latitudes wrapping up anticyclonically and developing into a cutoff anticyclone at high latitudes. In Thiéblemont et al. [2011], we suggested that this mechanism may similarly apply in the case of FrlACs in the middle stratosphere, with an easterly QBO phase leading to a strengthened anticyclonic shear between tropics and midlatitudes and thus leading poleward tropical/subtropical intrusions to wrap up anticyclonically and to develop into FrlACs. This proposed mechanism is consistent with both the increased FrlAC frequency under permanent tropical easterlies and the significant easterly anomalies associated with FrIACs when the QBO is nudged (Figure 12).

To further test the suggested connection between the QBO phase and the wave breaking geometry in the polar region, focused model sensitivity studies are needed. A set of CESM(WACCM) experiments, similar to our NoQBO experiment but with various constant zonal wind forcing values in the tropical region, may help understand the influence of the subtropical gradient wind on wave breaking. Finally, we note that wave propagation and wave-mean flow interaction in the stratosphere can be influenced by the QBO nudging procedure [Hansen et al., 2013]. Furthermore, prescribing the QBO limits the potential feedback between the middle to high latitude and the tropics. To represent all the processes involved in the modulation of poleward wave breaking by the QBO realistically, experiments with an internally generated QBO would be necessary.

The CESM(WACCM) simulations were performed at the Deutsche Klimarechenzentrum (DKRZ) Hamburg, Germany. This work was partly supported by the LABEX Voltaire ANR-10LABX-100-01 from the French agency ANR. We are grateful to Christoph Petrick and Wuke Wang for setting up some of the fully coupled model experiments used in this study. We also thank Peter Hitchcock, Daniela Domeisen, and Sabine Haase for helpful discussions. Rémi Thiéblemont thanks Slimane Bekki and the STRATO research team of the LATMOS institute for their warm welcome. We thank the two anonymous reviewers for their helpful comments. Model data and codes used in this study are archived at the GEOMAR's server and are available on request by contacting the corresponding author at remi.thieblemont@latmos. ipsl.fr. The source code of the

Community Earth System Model version 1.0 (CESM 1.0) used in this study is publicly distributed and can be obtained after registration at http:// www.cesm.ucar.edu/models/cesm1.0/. ERA-Interim data used in this study are available at http://apps.ecmwf.int/datasets/ following registration.

\section{References}

Adams, C., et al. (2013), The spring 2011 final stratospheric warming above Eureka: Anomalous dynamics and chemistry, Atmos. Phys. Chem., $13,611-624$.

Allen, D. R., and N. Nakamura (2003), Tracer equivalent latitude: A diagnostic tool for isentropic transport studies, J. Atmos. Sci., 60, 287-304. Allen, D. R., A. R. Douglass, G. L. Manney, S. E. Strahan, J. C. Krosschell, J. V. Trueblood, J. E. Nielsen, S. Pawson, and Z. Zhu (2011), Modeling the frozen-in anticyclone in the 2005 Arctic summer stratosphere, Atmos. Chem. Phys., 11, 4557-4576, doi:10.5194/acp-11-4557-2011.

Allen, D. R., A. R. Douglass, G. E. Nedoluha, and L. Coy (2012), Tracer transport during the Arctic stratospheric final warming based on a 33year (1979-2011) tracer equivalent latitude simulation, Geophys. Res. Lett., 39, L12801, doi:10.1029/2012GL051930.

Allen, D. R., A. R. Douglass, and S. E. Strahan (2013), The large-scale frozen anticyclone in the 2011 Arctic summer stratosphere, J. Geophys. Res. Atmos., 118, 2656-2672, doi:10.1002/jgrd.50256.

Ayarzagüena, B., and E. Serrano (2009), Monthly characterization of the tropospheric circulation over the Euro-Atlantic area in relation with the timing of stratospheric final warming, J. Clim., 22, 6313-6324.

Bailey, S. M., B. Thurairajah, C. E. Randall, L. Holt, D. E. Siskind, V. L. Harvey, K. Venkataramani, M. E. Hervig, P. Rong, and J. M. Russell III (2014), A multi tracer analysis of thermosphere to stratosphere descent triggered by the 2013 stratospheric sudden warming, Geophys. Res. Lett., 41, 5216-5222, doi:10.1002/2014GL059860.

Black, R. X., B. A. McDaniel, and W. A. Robinson (2006), Stratosphere-troposphere coupling during spring onset, J. Clim., 19, 4891-4901.

Butchart, N., and E. E. Remsberg (1986), The area of the stratospheric polar vortex as a diagnostic for tracer transport on an isentropic surface, J. Atmos. Sci., 43(13), 1319-1339.

Butler, A. H., D. J. Seidel, S. C. Hardiman, N. Butchart, T. Birner, and A. Match (2015), Defining sudden stratospheric warmings, Bull. Am. Meteorol. Soc., 96, 1913-1928, doi:10.1175/BAMS-D-13-00173.1.

Dee, D. P., et al. (2011), The ERA-Interim reanalyses: Configuration and performance of the data assimilation system, Q. J. R. Meteorol. Soc., 137, 553-597, doi:10.1002/qj.828. 
Dickinson, R. E. (1973), Method of parameterization for infrared cooling between altitudes of 30 and 70 kilometers, J. Geophys. Res., 78 , 4451-4457, doi:10.1029/JC078i021p04451.

Durry, G., and A. Hauchecorne (2005), Evidence for long-lived polar vortex air in the mid-latitudes summer stratosphere from in situ laser diode $\mathrm{CH}_{4}$ and $\mathrm{H}_{2} \mathrm{O}$ measurements, Atmos. Chem. Phys., 5, 1467-1472.

Fairlie, T. D. A. (1995), Three-dimensional transport simulations of the dispersal of volcanic aerosol from Mount Pinatubo, Q. J. R. Meteorol. Soc., 121, 1943-1980.

Gent, P. R., et al. (2011), The Community Climate System Model Version 4, J. Clim., 24(19), 4973-4991, doi:10.1175/2011JCLI4083.1.

Gray, L. J., S. J. Phipps, T. J. Dunkerton, M. P. Baldwin, E. F. Drysdale, and M. R. Allen (2001), A data study of the influence of the equatorial upper stratosphere on Northern Hemisphere stratospheric sudden warmings, Q. J. R. Meteorol. Soc., 127, $1985-2003$.

Hansen, F., K. Matthes, and L. J.Gray (2013), Sensitivity of stratospheric dynamics and chemistry to QBO nudging width in the chemistry-climate model WACCM, J. Geophys. Res. Atmos., 118, 10,464-10,474, doi:10.1002/jgrd.50812.

Hansen, F., K. Matthes, C. Petrick, and W. Wang (2014), The influence of natural and anthropogenic factors on major stratospheric sudden warmings, J. Geophys. Res. Atmos., 119, 8117-8136, doi:10.1002/2013JD021397.

Hardiman, S. C., et al. (2011), Improved predictability of the troposphere using stratospheric final warmings, J. Geophys. Res., 116, D18113, doi:10.1029/2011JD015914.

Harvey, V. L., R. B. Pierce, T. D. Fairlie, and M. H. Hitchman (2002), A climatology of stratospheric polar vortices and anticyclones, J. Geophys. Res., 107(D20), 4442, doi:10.1029/2001JD001471.

Haynes, P. H. (1990), High-resolution three-dimensional modelling of stratospheric flows: Quasi-two dimensional turbulence dominated by a single vortex, in Topological Fluid Mechanics, edited by H. K. Moffat and A. Tsinober, pp. 345-354, Cambridge Univ. Press, New York.

Haynes, P. H., and M. E. McIntyre (1990), On the conservation and impermeability theorems for potential vorticity, J. Atmos. Sci., 47(16), 2021-2031.

Hess, P. G. (1990), Variance in trace constituents following the final stratospheric warming, J. Geophys. Res., 95, 13,765-13,779, doi:10.1029/ JD095iD09p13765.

Hess, P. G. (1991), Mixing processes following the final stratospheric warming, J. Atmos. Sci., 48, 1625-1641.

Hitchcock, P., T. G. Shepherd, and G. L. Manney (2013a), Statistical characterization of Arctic polar-night jet oscillation events, J. Clim., 26, 2096-2116, doi:10.1175/JCLI-D-12-00202.1.

Hitchcock, P., T. G. Shepherd, M. Taguchi, S. Yoden, and S. Noguchi (2013b), Lower-stratospheric radiative damping and polar-night jet oscillation events, J. Atmos. Sci., 70, 1391-1408, doi:10.1175/JAS-D-12-0193.1.

Holton, J. R., and H.-C. Tan (1980), The influence of the equatorial quasi-biennial oscillation on the global circulation at $50 \mathrm{mb}, \mathrm{J}$. Atmos. Sci., $37,2200-2208$.

Holton, J. R., and H.-C.Tan (1982), The quasi-biennial oscillation in the Northern Hemisphere lower stratosphere,J. Meteorol. Soc.Jpn.,60, 140-148.

Kinnison, D. E., et al. (2007), Sensitivity of chemical tracers to meteorological parameters in the MOZART-3 chemical transport model, J. Geophys. Res., 112, D20302, doi:10.1029/2006JD007879.

Knox, J. A., and V. L. Harvey (2005), Global climatology of inertial instability and Rossby wave breaking in the stratosphere, J. Geophys. Res., 110, D06108, doi:10.1029/2004JD005068.

Labitzke, K. (1981), Stratospheric-mesospheric midwinter disturbances: A summary of observed characteristics, J. Geophys. Res., 86, 9665-9678, doi:10.1029/JC086iC10p09665.

Lahoz, W. A., A. J. Geer, and Y. J. Orsolini (2007), Northern Hemisphere stratospheric summer from MIPAS observations, Q. J. R. Meteorol. Soc., $133,197-211$

Lean, J. L., G. Rottman, J. Harder, and G. Kopp (2005), Source contributions to new understanding of global change and solar variability, Sol. Phys., 230, 27-53, doi:10.1007/s11207-005-1527-2.

Li, Q., H. F. Graf, and M. Georgietta (2007), Stationary planetary wave propagation in Northern Hemisphere winter - Climatological analysis of the refractive index, Atmos. Chem. Phys., 7, 183-200.

Manney, G. L., N. J. Livesey, C. J. Jimenez, H. C. Pumphrey, M. L. Santee, I. A. MacKenzie, and J. W. Waters (2006), EOS Microwave Limb Sounder observations of "frozen-in" anticyclonic air in Arctic summer, Geophys. Res. Lett., 33, L06810, doi:10.1029/2005GL025418.

Manney, G. L., et al. (2011), Unprecedented Arctic ozone loss in 2011, Nature, 478, 469-475.

Manney, G. L., Z. D. Lawrence, M. L. Santee, N. J. Livesey, A. Lambert, and M. C. Pitts (2015), Polar processing in a split vortex: Arctic ozone loss in early winter 2012/2013, Atmos. Chem. Phys., 15, 5381-5403.

Marsh, D., M. . J. Mills, D. . E. Kinnison, J.-F. Lamarque, N. Calvo, and L. . M. Polvani (2013), Climate change from 1850 to 2005 simulated in CESM1(WACCM), J. Clim., 26, 7372-7391, doi:10.1175/JCLI-D-12-00558.1.

Matthes, K., D. . R. Marsh, R. . R. Garcia, D. . E. Kinnison, F. Sassi, and S. Walters (2010), Role of the QBO in modulating the influence of the 11 year solar cycle on the atmosphere using constant forcings, J. Geophys. Res., 115, D18110, doi:10.1029/2009JD013020.

Meinshausen, M., et al. (2011), The RCP greenhouse gas concentrations and their extensions from 1765 to 2300, Clim. Change, 109(1-2), 213-241, doi:10.1007/s10584-011-0156-z.

Naujokat, B. (1986), An update of the observed quasi-biennial oscillation of the stratospheric winds over the tropics, J. Atmos. Sci., 43, $1873-1877$.

Orsolini, Y.J.(2001), Long-lived tracer patterns in the summer polar stratosphere, Geophys. Res. Lett., 28, 3855-3858, doi:10.1029/2001GL013103.

Peters, D., and D. W. Waugh (1996), Influence of barotropic shear on the poleward advection of upper tropospheric air, J. Atmos. Sci., 53, 3013-3031, doi:10.1175/1520-0469(1996)053<3013:IOBSOT>2.0.CO;2.

Siskind, D. E., D. R. Allen, C. E. Randall, V. Lynn Harvey, M. E. Hervig, J. Lumpe, B. Thurairajah, S. M. Bailey, and J. M. Russell III (2015), Extreme stratospheric springs and their consequences for the onset of polar mesospheric clouds, J. Atmos. Sol. Terr. Phys., 132, 74-81, doi:10.1016/j. jastp.2015.06.014.

Stratosphere-troposphere Processes And their Role in Climate (SPARC) (2010), SPARC CCMVal Report on the Evaluation of Chemistry-Climate Models, edited by V. Eyring, T. Shepherd, and D. Waugh, SPARC Report No., 5, WCRP-30/2010, WMO/TD - No. 40. [Available at www.sparcclimate.org/publications/sparc-reports/.]

Thiéblemont, R., N. Huret, Y. J. Orsolini, A. Hauchecorne, and M.-A. Drouin (2011), Frozen-in anticyclones occurring in polar Northern Hemisphere during springtime: Characterization, occurrence and link with quasi-biennial oscillation, J. Geophys. Res., 116, D20110, doi:10.1029/2011JD016042.

Thiéblemont, R., Y. J. Orsolini, A. Hauchecorne, M.-A. Drouin, and N. Huret (2013), A climatology of frozen-in anticyclones in the spring arctic stratosphere over the period 1960-2011, J. Geophys. Res. Atmos., 118, 1299-1311, doi:10.1002/jgrd.50156.

Waugh, D. W., and P.P. Rong (2002), Interannual variability in the decay of lower stratospheric Arctic vortices, J. Meteorol. Soc. Jpn., 80, $997-1012$.

Wei, K., W. Chen, and R. H. Huang (2007), Dynamical diagnosis of the breakup of the stratospheric polar vortex in the Northern Hemisphere, Sci. China Ser. D, 50(9), 1369-1379, doi:10.1007/s11430-007-0100-2. 